ESJ Humanities

\title{
Language and Sexism: The Use of English Language as Academic Discourse in Balamban, Cebu Primary Education Textbooks
}

\author{
Lea Ann A. Villanueva \\ Geronimo Obaob
}

College of Teacher Education, Cebu Normal University 6000, Philippines

\section{Doi:10.19044/esj.2021.v17n24p132}

Submitted: 01 June 2021

Accepted: 01 July 2021

Published: 31 July 2021
Copyright 2021 Author(s)

Under Creative Commons BY-NC-ND

4.0 OPEN ACCESS

Cite As:

Villanueva L.A.A. \& Obaob G. (2021). Language and Sexism: The Use of English Language as Academic Discourse in Balamban, Cebu Primary Education Textbooks. European Scientific Journal, ESJ, 17(24), 132. https://doi.org/10.19044/esj.2021.v17n24p132

\section{Abstract}

It is important to analyse textbooks in primary education from a gender perspective because textbooks, in addition to family and society, play an important role in the socialization of children. Thus, this study aims to analyse and review gender roles as well as the use of the English language as academic communication in selected primary education textbooks. Furthermore, 5 primary school teachers were also interviewed to know their perceptions of gender roles. Qualitative content analysis and data collection methods were used. The texts and illustrations of the textbooks were content analyses and it was found out that these selected textbooks were male-based in texts, illustrations, and language. The textbooks portray men in active roles mostly in Science related fields while women were depicted in conformity with the expected traditional Filipino culture of women; dependent, take care of the household, and passive. Findings from teacher interviews correspond to the findings from the textbook analysis. It shows that almost all teachers admitted that women/men are not treated equally but at the same time in some instances, they believed that roles or occupations that require physical strength and competence should be male-exclusive. When it comes to women's roles outside the home, the interviewed male teachers wanted these roles to be in conformity with the traditional Filipino culture where women stay in the house and take care of the babies, and do most of the household works. The 
interviewed female teachers react in opposition saying that the current Philippine societal set-up no longer requires women to stay at home perform traditional expected roles of women, stating that male teacher's conclusion as to the roles of women outside the home indicates deeply rooted beliefs perpetuating the unequal treatment of girls and boys in Philippine families, schools, and society. The research comes to a number of conclusions and also recommends more research with a wider scope that includes interviews and analysis from an increased number of teachers, students, textbook reformers, and policymakers to get a wider picture of gender roles.

Keywords: Language and sexism, gender-fair language, gender-inclusive education in the Philippines, primary education textbooks, gender perspective analysis

\section{Introduction}

A sex-specific jargon still governs the English language. Hunk is a euphemism for males, and a chick is a term for women. It can be argued that the jargon used to define men and women needs to be changed (Nneka, 2012).

The apathetic shift from gender discrimination in education to gender sensitivity is always a challenge for social science. Even with the progress in gender parity, the Philippines is still a long way from achieving gender inclusivity and equality in education (Morales, Avilla, \& Espinosa, 2016).

The Philippines has long been a country where people have been treated differently depending on their gender. The government's attempt to mainstream gender-and-development education in schools is being challenged. Women's participation in society spanned three decades of the women's suffrage movement (Tarrayo, 2021).

Instead, the Philippine Education Department issued a Genderresponsive Basic Education policy. This policy commits to incorporating the principles of gender equality, gender equity, gender sensitivity, nondiscrimination, and human rights in the provision and governance of basic education. Thus, this raises the following key issues: (1) How will this policy and these facts influence the current educational setup in the Philippines? (2) Why is textbook analysis from a gender perspective important in achieving an education that guarantees that girls and boys are empowered equally in and through education?

\section{Gender and Education- Legal Framework}

The Philippine Education for All (EFA) 2015 is a vision and holistic reform effort to promote basic education for every Filipino by 2015. Considering that this policy is rather recent (2015 onwards) in the Philippines, it is deemed appropriate for the government to address, through this vision, 
the 1948 United Nations Declaration of Human Rights. This policy further accentuates the objective of education to contribute to the entire development of human personality and respect for liberties, and it also allows parents to pick the type of education to be delivered to their children (UN Declaration on Human rights, 1948, Article 26).

The UN Convention on the Elimination of Discrimination Against Women (CEDAW), adopted by the UN General Assembly in 1979 and entered into force in 1981, also refers to equal education for men and women in Articles 10a and 10b. Furthermore, as per the convention, states should ensure that gender discrimination is eliminated and that men and women have equal access to higher education. Based on the current convention "at all levels and in all systems of learning, it is very important to eliminate any stereotyped concept of men and women's roles by encouraging coeducation and other types of education that will help to achieve this goal, in particular, by the revision of textbooks and school programmes and the adaptation of teaching methods" (Fahim, 2010 through CEDAW, 1981, Article 10c).

\section{Theories of Gender in Education and Context of Textbooks}

Gender stabilization replaced the previous "sexism" and "gender discrimination" lexicon. Terms like "gender" instead of "sex" and "police officer" instead of "police man" were used to describe things or people not related to either women or men, reflecting a new view of gender inclusivity. According to Kollberg (2015), however, the language used in learning materials can influence how students perceive their surroundings.

Moreover, this research aligns with and relates to Edward Sapir and his pupil, Benjamin Lee Whorf's Linguistic Relativity Hypothesis, who claims that the world's notions of speakers may be adversely affected by the language they use. In his essay titled "The Status of Linguistics as a Science" (1961), American anthologist and linguist E. Sapir exemplified the principle reformulated by B.L. Whorf in his published essay "Science and Linguistics." They were deeply interested in linguistic determinism (the idea that your language shapes how you think) and that language's power to change our perceptions and create reality is undeniable. Although this hypothesis has ignited discourse since its launch, it has the insinuation that if reality is perceived and structured by the language we speak, the existence of an objective world is called into question, and any scientific knowledge we acquire is bound to be subjective. Then a relativistic principle becomes a deterministic principle (Hussein, 2012).

This paper analyzes and reviews English as an academic communication medium in primary education textbooks from the University of San Jose-Recoletos in the academic year 2020 to 2021. These textbooks include (1) Science and Technology, (2) Reading and Writing, (3) Language, 
(4) Home Economics and Livelihood Education, and (5) Christian Living Formation.

\section{Method}

\section{Data and Sample Selection}

At the University of San Jose Recoletos in Balamban, Philippines, data was collected through five interviews with teachers (two men and three women) in various disciplines in primary education. The interviewees were based purely on their expertise in the area. The teachers were asked five openended questions (for interview questions, see Annexe two). A letter explaining the study's purpose and the setting was sent to participants and questionnaires for the interview, and checklists as attachments. The teachers interviewed ranged in age and had varying levels of teaching experience. The research was carried out entirely online by using Google Forms as the platform. The respondents completed the checklist mentioned above, which detailed the nature, categories, and features of textbook analysis. The researcher approved the study for primary education textbooks in Home Economics and Livelihood Education, Language, Christian Living Formation, Reading and Writing, and Science.

Interviews were conducted in English by using a semi-structured checklist to allow the teacher to review the textbook beforehand. The researcher used a general questionnaire that guided the entire interview to ensure that all questions were retrieved. Firstly, the teacher was asked about the current roles of girls/women in the current Philippine educational set-up? Secondly, the teacher was asked if the specified primary textbook promotes gender equality based on a checklist that the teacher had completed previously. Thirdly, they were asked to rate a textbook based on the author's gender, title, statements about girls and boys, examples used in lessons, and illustrations. Fourthly, the teacher was asked to suggest ways to improve the textbook's language and illustrations. Finally, the teacher was questioned about her opinion of gender-inclusive books and her general idea about them. Aside from that, each interview was promising because each teacher has his or her pedagogical convictions and goals.

\section{Method for Analysis}

The researcher utilised content analysis, which can be qualitative or quantitative, to assess textbooks. The existence or lack of target words, images, and messages is scrutinised in quantitative content analysis, whereas implicit or underlying meaning is investigated in qualitative data analysis (Ozdogru \& Erdogan, 2002). Both texts and illustrations were analyzed in this study because they are equally important. The portrayal of male and female characters in texts and illustrations impacts the formation of stereotypes and 
beliefs about male and female gender roles. The researcher used qualitative content analysis to reach his research objectives by assessing how genderrelated character traits are presented, the categories of bias made, the interactions of both sexes, statements describing gender-related traits, and illustrations and graphic design. Furthermore, the same content analysis was used during the transcriptions of teacher interviews.

The researcher, however, decided to conduct the study online due to the circumstances that people are facing during the pandemic. Different grids were generated to count male and female characters in text and illustrations while also recording their associated characteristics, which asserted to be highly valuable (to see the checklist, see Annexe one). For instance, whether male and female characters are presented static or in interaction was investigated. In interactions, observations were made about the essence of the interactions (i.e., family interactions, professional interactions, interactions reflecting gender-exclusive relationship, violent interaction, affective interaction, academic interaction). A model proposed by Blumberg (2007) was taken into account for steering different subject teachers in answering the checklist. The model identifies the following gender bias analytical categories.

\begin{tabular}{|l|l|l|}
\hline $\begin{array}{l}\text { Category of Gender } \\
\text { Bias }\end{array}$ & Definition & Examples \\
\hline Invisibility & $\begin{array}{l}\text { Complete or relative exclusion of } \\
\text { a group. }\end{array}$ & $\begin{array}{l}\text { For instance, } \\
\text { In some languages, the terms } \\
\text { used for different occupations } \\
\text { suggest that either women or men } \\
\text { are excluded from practicing } \\
\text { them. } \\
\text { A powerful gender imbalance (or } \\
\text { total lack of one or the other } \\
\text { gender characters) in examples } \\
\text { and/or illustrations. }\end{array}$ \\
\hline Stereotyping & $\begin{array}{l}\text { Unfair assignment of } \\
\text { characteristics to a group of } \\
\text { people, at the cost of individual } \\
\text { attributes and differences. } \\
\text { Stereotyping may contain either } \\
\text { offensive or flattering statements } \\
\text { and situations, depending on the } \\
\text { positive or negative prejudices } \\
\text { they promote. }\end{array}$ & $\begin{array}{l}\text { For instance, } \\
\text { The belief that women are usually } \\
\text { emotional, while men are not. } \\
\text { The belief that men are good with } \\
\text { technology, while women are not. } \\
\text { The belief that men are better } \\
\text { organized than women and more } \\
\text { efficient leaders. } \\
\text { Representation of inanimate } \\
\text { objects as he/she by determining } \\
\text { its qualities and/or characteristics } \\
\text { to be of man or women. }\end{array}$ \\
\hline $\begin{array}{l}\text { Imbalance and } \\
\text { selectivity }\end{array}$ & $\begin{array}{l}\text { Presenting only one interpretation } \\
\text { of an issue, situation, or group of } \\
\text { people. }\end{array}$ & $\begin{array}{l}\text { For instance, } \\
\text { While talking about heroism or } \\
\text { excellence in areas like science } \\
\text { and technology, only men are } \\
\text { mentioned. }\end{array}$ \\
\hline
\end{tabular}




\begin{tabular}{|c|c|c|}
\hline & & $\begin{array}{l}\text { While referring to household, } \\
\text { only women are being refered to } \\
\text { as someone who takes care of the } \\
\text { house and children. }\end{array}$ \\
\hline Unreality & $\begin{array}{l}\text { Ignoring unpleasant aspects in } \\
\text { favour of flattering ones. }\end{array}$ & $\begin{array}{l}\text { For instance, } \\
\text { Avoiding portraying sensitive } \\
\text { aand unpleasant aspects in family } \\
\text { life, such as domestic volence, } \\
\text { especially against women. } \\
\text { Avoiding portratying issues such } \\
\text { as women's exploitation or the } \\
\text { fact that women are sometimes } \\
\text { considered as socially inferior. }\end{array}$ \\
\hline $\begin{array}{l}\text { Fragmentation and } \\
\text { isolation }\end{array}$ & $\begin{array}{l}\text { Presentation of non-dominant } \\
\text { group as peripheral members of } \\
\text { society. }\end{array}$ & $\begin{array}{l}\text { For instance, } \\
\text { Narrative and illustrrations of } \\
\text { different situations where women } \\
\text { are always underrepresented. }\end{array}$ \\
\hline Cosmetic biases & $\begin{array}{l}\text { Things seemed to have been } \\
\text { "corrected"/ improved in books, } \\
\text { but biases persist in different } \\
\text { ways. }\end{array}$ & $\begin{array}{l}\text { For instance, } \\
\text { The fact that while they appear to } \\
\text { be an equal number of men and } \\
\text { women in illustrations, no } \\
\text { relevant examples are given as } \\
\text { significant achievements of } \\
\text { women in different areas. }\end{array}$ \\
\hline $\begin{array}{l}\text { Generic use of } \\
\text { "Man" }\end{array}$ & $\begin{array}{l}\text { Excessive use of the term "man" } \\
\text { in describing the wholeness of } \\
\text { someone or something. }\end{array}$ & $\begin{array}{l}\text { For instance, } \\
\text { Statements using terms like } \\
\text { "brotherhood" or "mankind" and } \\
\text { other masculine "generics." }\end{array}$ \\
\hline
\end{tabular}

\section{Results}

The researcher and interviewees carried out a review, assessment, and interview on school textbooks, and it was anticipated that several important aspects of textbooks' contribution to promoting gender equality could be established. Stereotyping, fragmentation, the invisibility of women in illustrations, and the assumption that the generic default in English as academic communication was typically masculine were the most prominent categories of prejudice that surfaced. Areas of study were also used to present the research findings.

\section{Science and Technology Textbook Review}

The majority of graphics in Science and Technology curriculums are not gender-inclusive or sensitive to gender. Although there is only one confirmed prejudice in the book's depictions of men, there are several biases in its representation of women. The book's biases include fracturing and isolation, as well as the overall use of the term "man". Images of men as strong 
(p. 114, 297) and captions that commence with the statement, "A man is applying/cycling/climbing..." (p. 312-319) are routinely utilised. Hence, this can spur to a context of dominance for men and subjugation for women since men and women have various roles. As a consequence, in opposition, gender differences are accepted.
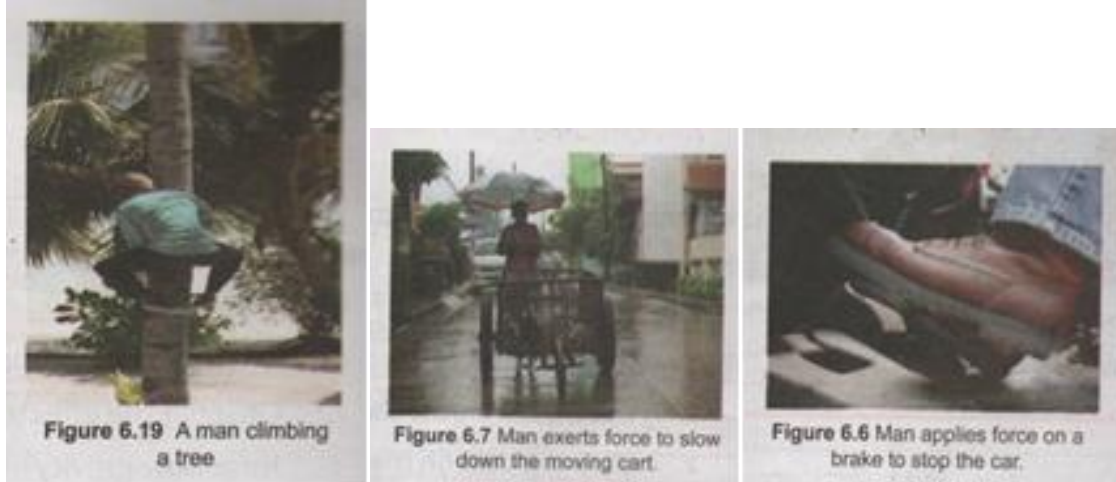

Figure 6.6 Man apples force on a brake to stop the car.
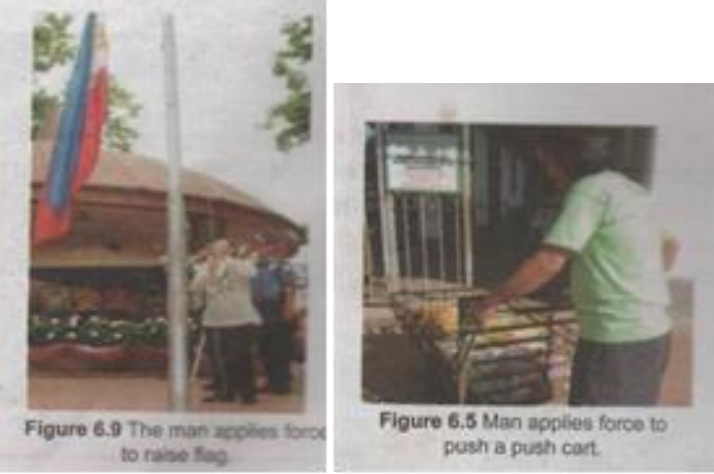

Conell asserted in her book Gender that "women are supposed to be nurturing, suggestible talkative, emotional, intuitive, and sexually loyal, whilst men are supposed to be hostile, tough-minded, taciturn, rational, analytic, and promiscuous." In his book, Conell argues that people are treated differently because of their gender owing to assumed "sex roles".

Moreover, the findings further showed that both men and women are exposed to a multitude of violations. Stereotyping is a common form of sexism that influences both men and women. It was exhibited in the book's "Healthy Habits to Keep the Skeletal System Healthy" topic that women should dance as a healthy practice and men should bicycle. When a child sees these examples, the idea imposes and forces the child to do tasks that he or she does not want.

Furthermore, gender stereotypes and social norms are segregated by a curriculum. Since these ideas are considered customary behaviours, we cannot force a child to become a strong man or a flexible woman. In the Philippines, 
women are viewed from the perspective of Filipino culture, standards, and mindset. The ideal Filipina (Philippine woman) is a docile woman who looks after and nurtures her children while still caring for most household chores. The preference of most families for male children over female children was also a trait found all across Asia (Almond, Edlund, \& Milligan, 2013).

\section{Reading and Writing Textbook Review}

The curriculum design development was focused on the reading competencies in the $\mathrm{K}$ to 12 Curriculum Guide, as per the foreword of the said textbook. The article was based on Krashen's language acquisition theory, which accentuates that "the focus of the learning process is comprehension and enjoyment of the text, indirect language learning becomes even more effective." As stated by Goodman, "Reading is a psycholinguistic guessing game, which points to the role of schema or background knowledge in getting the meaning of the text."

Likewise, these are the same theories on which this study is based. It is focused primarily on how textbooks add new meaning and the use of this meaning to create an efficient and long-lasting concept that can be used in the new curriculum. However, the use and production of the English language are not entirely dependent on lexical semantics. The medium's context reinforces the theory that vocabulary is being used to communicate feelings, thoughts, ideas, and aspirations. It also addresses issues that are often disregarded or ignored when teaching English. Statements and titles of stories usually encounter gender bias, according to the respondent's general questionnaire and checklist, because the author frequently uses gendered pronouns with statements that do not demand them, including hero/heroine (p 12), his/her work (p 19), and him/her as a community helper (p 23).

Stereotyping is a prevalent form of prejudice that negatively impacts both men and women. "While the girls screamed, Art chased the mouse." is an example of a statement that disparages girls and women. As a result, the expectations for men and boys are growing steadily. We start imposing on our learners a worn-out, impractical, and nonsensical belief that "women should do household chores while men go to work" (p 29, 30, 31, and 55). Men are no longer presumed to do physical labour, and women were not intended to stay at home. Even today, messy men get a pass while messy women go unnoticed because we persist in inculcating in the minds of succeeding generations that housework is still considered women's work, notably for women who live with men. These are just a few of the book's examples of how women are treated and described. 


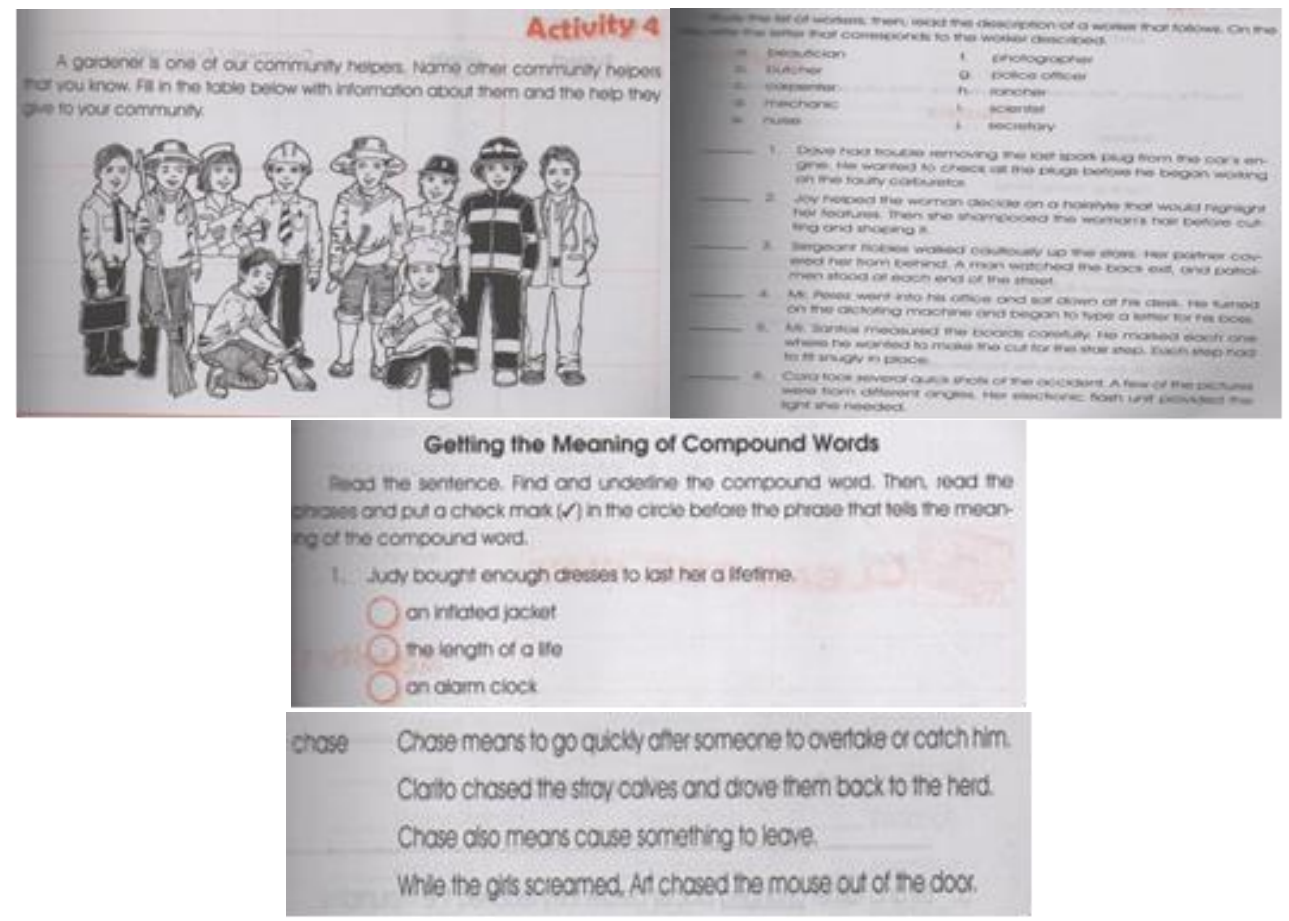

\section{Language Textbook Review}

Communication and comprehension are the two most important factors that people need today. Communication and comprehension are two skills needed to be developed by the future generation, which may lead to problems if not fully developed. Authenticity in education is what the author aims for in the said textbook, which aligns with the $\mathrm{K}$ to 12 core standards.

The author believes that relevance, reliability, and innovation provide authentic education to our 21st-century learners. This book stresses traditional grammar and emphasizes the speaking and writing aspects of the English language. It is composed of seven (7) sections that further elaborates and measures the understanding and application of the child's knowledge.

The first section titled "Break In" educates the learner more about skills and values to be learned through process questions followed and connected to the lesson development, which provides the target skill discussion. The second section, Focus, provides opportunities for functional language use through activities. The Enrich Language Use section provides activities for the improved outcome of the skills learned in the lesson, and the Information and Communication Technology Integration section provides the fourth section. The fifth section, Perform, gives learners task-based activities to place their newly acquired focus skills to use. The sixth section, Do not Forget, provides reminders about sound values, good manners, and proper conduct. Alternative forms of self-assessment designed to measure the pupil's 
performance in the skills gained are provided in the seventh section, Check Your Progress, with rubrics and checklists. A list of the main points encompassed in each lesson is included at the end of each unit and serves as a reviewer for the summative test.

Only a few violations were discovered in the entire textbook, as per the researcher's and interviewee's examination and cross-checking. These errors are constantly made through their graphic and illustration designs rather than through statements, stories, or examples. Gender disparity and selectivity seem to have been two types of bias that were regularly used.
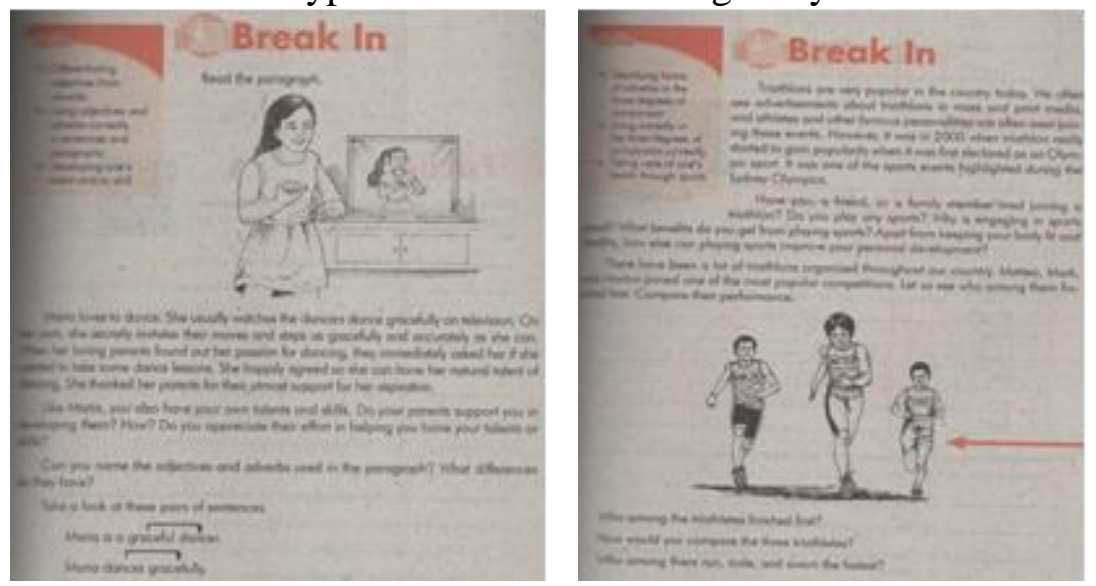

The interaction of these images regularly conveys a more genderexclusive relationship, which leads to the perceived notion that women are underrepresented in the pictures and that the selection of these images is inaccurate. The unit's cover page is particularly reliant on men and their achievements (professionally or academically), exemplifying women's invisibility and fragmentation.
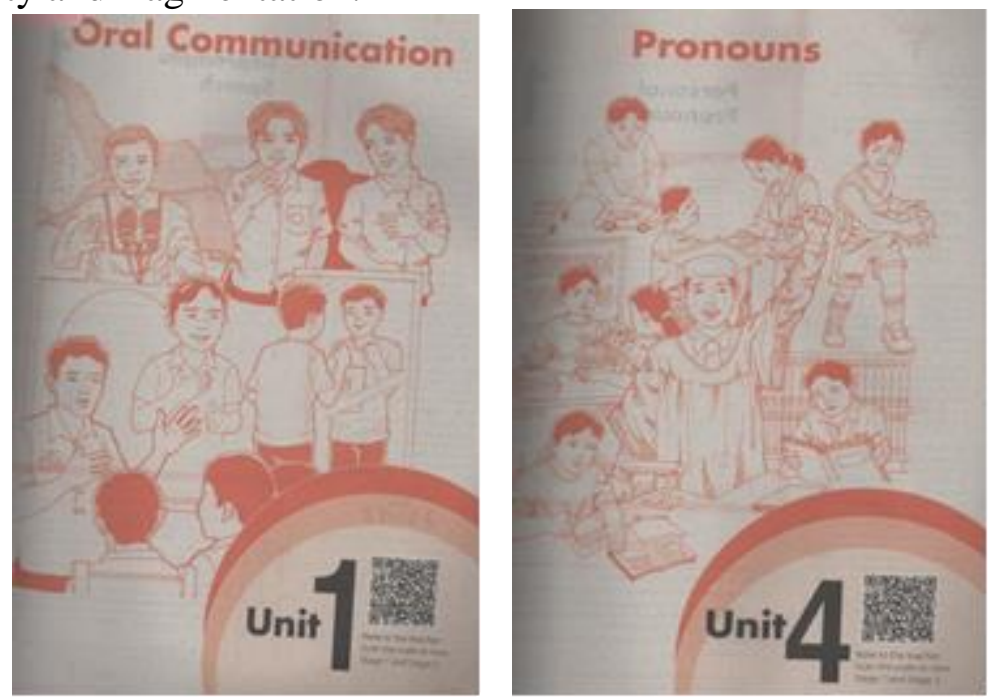
However, thistransforms sentences to make them sound more appropriate. On page 58, the author provides ten sentences wherein the students are asked to identify the function of the outlined nouns. The author uses "Dr. Rubio" as the subject in sentences 1-7 without acknowledging the subject's gender. She introduced "Tina" (who is currently enrolled in a medical programme) as "Dr. Rubio's" daughter in sentence 8 of the same activity. By adding the pronoun "his daughter," it is clear that "Dr. Rubio" is a man. However, because the author uses an obliterated term for the subject, the researcher and respondents realized that there was no bias in the stated sentences.

The book's advantages include:

1. Empowering students' creativity in presenting a situation and a topic;

2. Problem-solving and decision-making as crucial skills to be developed by learners on each topic presented; and

3. Most importantly, the use of a second-person point of view, which differs significantly from the traditional use of gendered pronouns.

\section{Home Economics and Livelihood Education Textbook Review}

Home economics education is a field of study which incorporates concepts, principles, and theories from different areas of home economics, including food and nutrition, shelter, clothing, family life, consumer, entrepreneurship, ICT integration, and livelihood education. It underlines decision-making and household resource management capacities. It takes the interaction between the material and relational aspects of day-to-day living severely. Through quality instruction, research and extension, the main goal of this programme is to develop learners who are exemplars of knowledge, skills, and humanitarian values committed to enabling individuals and families to become influential members of local and global communities.

Based on the researcher's and interviewee's analysis, it was assessed that the Home Economics and Livelihood Education textbook did not violate any of the researcher's presented bias categories. In terms of the interaction of women and men, the language used, examples and activities, illustrations and exercises followed a strict inclusion. Gender roles and norms were depicted in illustrations and graphics with a sense of balance and sensitivity. Traditional minds believe that HELE VI is solely for the benefit of women and girls because it focuses so little on home and family wellness, livelihood, and development. However, according to the review, the book did not focus on gender roles and expectations. As a result, there was no isolation, fragmentation, or cosmetic biases between or among genders in every illustration or example. It was constructed in such a way that the author and illustrator have been able to focus on women in all aspects of the book. 
Reviewing this textbook was crucial for more than just distinguishing gender biases, stereotypes, and discrimination. It is aimed at seeing if we were raising people who knew how to cook and stay safe and how to be accountable. It allows teenagers to adapt the techniques they learned in class and the book at home. When teenagers learn how to care for their home and, more importantly, themselves, they develop a greater understanding of social and cultural differences and the importance of accepting and respecting those differences.

Home economics is one of the few subjects in school that can significantly reduce gender misconceptions. It is a subject that encourages gender sensitivity and inclusion so that all genders are considered equal. In the textbook, it is clear how a simple illustration can shape a child's thinking. It has the potential to make or break a child's perspective of how his or her gender is defined in books and society's eyes. Therefore, this book refutes the stereotypical and misogynistic notion that women are only allowed to work at home.

Furthermore, it also implies that men are capable of breaking free from their stereotypes. On page 10 of the book, it depicts the dismantling of traditional gender roles and labels and provides learners with various educational and career options. It demonstrated that women could be "someone" in science and technology, farming, gadget production and repair, and household linen production, while men can be "someone" in the fields of animal husbandry, family resource management, and linen production. Thus, the book offers us limitless possibilities and boundless limitations on what we can become which have a significant effect on the minds of young students.

\section{Christian Living Formation Textbook Review}

The decline of morality is a significant issue confronting society today. Moral values are the code of conduct and life standards established by society or the international community as a whole. The first official state policy on values education is found in Article XIV, Section 8 of the Philippine Constitution, which states that "all educational institutions shall aim to develop moral character, personal discipline, civic conscience, and vocational efficiency, and teach the duties of citizenship," thus focusing the Philippines' experience in values development. According to Fyffe, Hay, and Plamer Education, issues and concerns in Children's Values, particularly values education, are frequently contentious, reflecting contradictory but deeply held beliefs among various segments of society about what constitutes core human values.

According to the interviewee, this textbook makes "abundant use of Scriptural citations with complementary references to the teachings of the Church as found particularly in the Catechism of Catholic Church (CCC), the 
Catechism for Filipino Catholics (CFC), and the Second Plenary Council of the Philippines (PCP II)'.

The book begins with a discussion of the lesson's main point or message, which is followed by concrete applications in daily life. Thereafter, it is elevated to prayer and further inculcated in the minds through specific and measurable exercises. Several Philippine schools offer Religion or Christian Living classes in Catholic, diocesan, or congregational schools and values education. This book is used in private non-sectarian schools across the country because it has an official declaration (Nihil Obstat and Imprimatur) free of doctrinal and moral errors (which is only a few in the Philippines).

This textbook is a gender-inclusive and gender-sensitive textbook that can be used by primary learners based on the findings of the researcher and the interviewee. Overall, the most common type of bias was stereotyping of how men and women were depicted in the illustrations and graphics. On page 64 , the illustration depicted all men as prisoners, while the women were depicted as butterflies. No statement or caption corresponds to the illustration. However, because a child has little idea of whom they can become, both genders must be represented neutrally in all cases.

The researcher perceived the neutralised idea of what the author wants to convey. In his statements and examples, the author is engrossed with the concept of equality.

When an illustration calls for a crowd of people, the picture always depicts an equal number of men and women. Fragmentation and isolation, cosmetic biases, and women's invisibility were hardly mentioned in the book's pages. Furthermore, the use of the fourth person point of view was consistently observed when describing and referring to men and women as a whole. While the voice may be imbued in the community, it is not tied to any individual consciousness, which is one of the advantages of using the fourth person perspective. The book's main point or message depicts several saintly women, their stories, talents, jobs, and other factors contributing to women's empowerment in general.

In contrast to the gender roles, men were also portrayed. Men have represented planting flowers and assisting with the domestic duties that are indeed a change of perception and view of how men can genuinely become. This contributes to the sense of acceptance and respect for what a boy wants to be and whom he chooses to be.

Moral growth begins when we comprehend the difference between right and wrong (Keung Ma, 1982) and how it might influence people around us, involving learning for youngsters if not properly guided. To utilise the example of how influential a values education textbook may be, authors and curriculum developers should recognise the importance of coming to the 
appropriate decision when faced with difficult choices in language and pictures provided by books.

\section{Discussion}

As the results convey, all teachers interviewed reflected the reviewed textbook and their language inside the classroom. All teachers considered having a gender-inclusive textbook as one factor that may help raise and teach gender-sensitive students; however, this is generally not guaranteed. One of the teachers stated that "once the textbooks comply with the Priority Gender Equality platform of UNESCO, and once the school selects textbooks efficiently and smartly, we serve the kind of instruction at its best."

Although textbooks have a powerful impact on teaching genderrespecting children, factors like language in the classroom, gender-sensitive curricula, and textbooks may not be enough to set school standards in full. Gender-fair language and practices help to give each gender more in-depth, meaningful definitions, and respect. Textbooks are the most tangible and visible part of a curriculum and the most frequently used tool for teachers and students (Hanoi, Do Son, \& Geneva, 2010).

In many parts of the world, textbooks still effectively drive learning and teaching rather than being used as one resource. Textbooks are the "tangible" curriculum closest to students' hearts and minds. As a result, textbook messages substantially impact learners (especially early years) and society more broadly. As printed materials, they enjoy widespread respect for the printed word. In many societies, one tends to think that anything written or printed in a book, including a textbook, must be correct and accurate (over time).

\section{Conclusion}

In illustrations and texts, female roles depict the most passive and stereotypical way by presenting them as someone who takes care of the house, worries about clothes to wear, or even invisibility in social roles. In comparison, men are depicted in more active roles inside and outside. Women are still less prominent than men as leading actors in texts and illustrations.

Moreover, women are in line with their "sex roles" as women's invisibility in the scientific and technical field is almost present among illustrations and statements. When they are depicted as working outside the home, they tend to take up traditionally female jobs such as teachers, office workers, and nurses. Women/girls tend to be portrayed as passive and dependent, while men/boys appear as more intellectual (being visible in fields related to science), active, and adventurous.

The analyzed texts used male-centered language or "Man" generic use. To all humans, male words and common nouns were used. Gender-exclusive 
interaction excludes women from the first page of the Science textbook, where only men were presented as remarkable scientists. Findings from the teacher interviews show that almost all teachers admitted that women/men are not treated equally, but at the same time, they believed that roles or occupations requiring physical strength and competence should be exclusive to men.

When it comes to women's roles outside the home, the male teachers interviewed wanted these roles to conform to the traditional Filipino culture where women stay in the house, take care of babies, and do most household work. However, the female teachers interviewed react in opposition that the current social set-up in the Philippines no longer requires women to stay at home to perform traditional expected roles of women. Therefore, the conclusion of male teachers as to the roles of women outside the home indicates deeply rooted beliefs perpetuating the unequal treatment of girls and boys in Philippine families, schools, and society.

By analyzing the selected textbooks and findings from teacher interviews, it can be concluded that the government has not fulfilled its promise of gender equality and non-discrimination by continually publishing books that are not analyzed and reviewed from a gender perspective. As a result, our current educational setup, patriarchal, traditional, and stereotypical socialization patterns emanating from our norms and values remain valid. Therefore, before we can achieve gender equality in education, we must first understand the factors contributing to this problem, address them individually, and find solutions that can have a significant positive effect on children.

We must consider the ongoing gender biases in these books so we can know what we are dealing with and how we can completely escape the raging gender issues in education. According to the Education Department's mandate to protect and promote quality, equitable, culture-based, and complete primary education on February 9, 2021, "the Department of Education does not tolerate discrimination based on race, gender, age, religion, or sexual orientation.

Indeed, when discussing discrimination and equal opportunities, one must think beyond girls' access to education or simply putting girls in schools. It is also important to keep girls in school and make educational achievements. This is possible, among other measures, if the learning environment and materials are not gender-based and conducive to girls' learning. Textbooks are not the only place where any bias (including gender biases) can occur. However, given their decisive role, especially in early school years (Daniels, 2020), it is critical to identify aspects that hinder gender equality.

Moreover, the author's language, graphics, and illustrations to create textbooks are extremely influential and provide a model for learners and society as a whole. Word choices often unconsciously reflect preconceived and wrong notions about gender roles. As a result, we should make conscious efforts not to use language that stereotypes, restricts, or excludes others. When 
education language is more inclusive, civic participation, employment, and community life are the same. Education excluding and segregating perpetuates discrimination against traditionally marginalized groups.

Consequently, given the limited scope of this research, examining different textbooks on primary education and interviewing only five teachers, future research with a wider scope is recommended in terms of content analysis of more textbooks from private and public schools and interviewing more teachers, students, policymakers, and textbook reformers to get a broader picture of gender roles. In all textbooks, it cannot be generalized that gender stereotypes is in the same way as generalized teachers' perceptions of gender. In future research, these limitations can be overcome by increasing research samples (in textbooks, schools, and teachers) and by including interviewing students. It will also be interesting to carry out a comparative study of newly revised textbooks and old textbooks to track improvements and revisions to depict male and female roles and occupations in texts and illustrations.

\section{References:}

1. Aspin David \& Chapman Judith (2007). Values Education and Lifelong Learning: Principles, Policies, Programmes. Published by Springer. Retrieved June 09, 2021 from https://link.springer.com/content/pdf/bfm\%3A978-1-4020-61844\%2F1.pdf

2. Bandura, A. (1999). "A Social Cognitive Theory of Personality" in Handbook of personality. L. Pervin and O. John (Ed.) (New York, US: Guilford Publications), 154-196.

3. Bergman, Z., Bergman, MM. \& Thatcher, A. (2019). Agency and Bandura's Model of Triadic Reciprocal Causation: An Exploratory Mobility Study Among Metrorail Commuters in the Western Cape, South Africa.

4. Blumberg, R.L. (2007). Gender Bias Textbooks: A Hidden Obstacle on the Road to Gender Equality in Education, UNESCO. Retrieved May 26, 2021, from http://unesdoc.unesco.org/images/0015/001555/155509e.pdf

5. Bosmajian, H. (1972). The Language of Sexism: A Review of General Semantics, 29(3), 305-313. Retrieved May 30, 2021, from http://www.jstor.org/stable/42576459

6. Daniles Nicole (2020). "What Role Should Textbooks Play in Education?" The New York Times, 14 January 2020, Retrieved 11 June 2021 from https://www.nytimes.com/2020/01/14/learning/whatrole-should-textbooks-play-in-education.html

7. Do Thi Bich Loan, Nguyen Thi Mai Ha, Kieu Thi Bich Thuy, Nguyen Tri, \& Trinh Thi Ahn (2016). Hoa. (n.d.). Guidelines for textbook 
review and analysis from a gender perspective [E-book]. https://docs.iiep.unesco.org/peic/2748.pdf

8. Fahim Ahmad Khalid (2010). Gender Issuess and Textbook: Gender Bias in Pashto Primary School Textbooks in Afghanistan. [E-book]. Retrieved June 09, 2021 from https://www.academia.edu/1762564/Gender_Issues_and_Textbooks

9. Hussein Basel Al-Sheikh (2012). The Sapir-Whorf Hypothesis Today.English Language and Literature. Retrieved June 11, 2021 from: https://www.academypublication.com/issues/past/tpls/vol02/03/30.pd $\mathrm{f}$

10. Islam Kazi Md. Mukitul \& Asadullah Niaz (2018). Gender Stereotypes and education: A Comparative Analysis of Malaysian, Indonesian, Pakistani and Bangladesh school textbooks. Retrieved June 11, 2021 from https://www.ncbi.nlm.nih.gov/pmc/articles/PMC5774688/

11. Kihlstrom, J.F, \& Park, L. (2021). "Cognitive Psychology: Overview" in Reference Module in Neuroscience and Biobehavioral Psychology (2018). Sapir-Whorf Hypothesis. Retrieved June 11, 2021 from https://www.sciencedirect.com/topics/psychology/sapir-whorfhypothesis

12. Kollberg, J. (2015). Gender Equality in EFL Classroom. A Qualitative Study of Swedish EFL Teachers' Perceptions of Gender Equality in Language and its Implementation in the Classroom

13. Llego Mark Anthony (2017). "Updated DepEd Gender-Responsive Basic Education Policy". TEACHERPH, June 29, 2017 Retrieved June 11, 2021 from https://www.teacherph.com/gender-responsive-policy/

14. Ma Hing-Keung (1982). A study of moral development with special reference to psychological needs, human relationships and structures of judgment. Retrieved June 08, 2021 from https://core.ac.uk/download/pdf/33678617.pdf

15. Morales, M.E., Avilla, R.A., \& Espinosa, A.A. (2016). Philippines is still far from achieving gender inclusivity and equality in education. Issues in Educational Research, 26(1) 60-70

16. Okeke, N.U. (2014). Sex-exclusive vocabularies where hunk is a term for men and chick is for women. pp.5 Retrieved May 26, 2021 from https://www.ajol.info/index.php/laligens/article/view/107910

17. Smelser \& Baltes (2001). Sapir-Whorf Hypothesis. International Encyclopedia of the Social Sciences. Retrieved May 25, 2021 from https://www.sciencedirect.com/topics/psychology/sapir-whorfhypothesis\#: :text=Edward\%20Sapir\%20and\%20his\%20pupil,of\%2 Odifferences\%20in\%20their\%20languages. 
18. Stokoe, E. (1998). Talking about gender: The conversational construction of gender categories in academic discourse. Discourse \& Society, 9(2), 217-240. Retrieved May 30, 2021 from http://www.jstor.org/stable/42888852

19. Tegelstrom Liv (2009). An English Language Textbook Study from a Gender Perspective. Retrieved June 11, 2021 from http://www.divaportal.org/smash/get/diva2:223322/FULLTEXT03

20. Timsit Annabelle (2017). "The Push to Make French Gender-Neutral." The Atlantic, 24 November 2017, Retrieved June 10, 2021 from https://www.theatlantic.com/international/archive/2017/11/inclusivewriting-france-feminism/545048/

21. UNESCO (2021). Education and gender equality. Retrieved June 10, 2021, from https://en.unesco.org/themes/education-and-genderequality

22. Wayne W. LaMorte (2019). The Social Cognitive Theory. Behavioral Change Models. Retrieved May 27, 2021 from: https://sphweb.bumc.bu.edu/otlt/mphmodules/sb/behavioralchangeth eories/behavioralchangetheories5.html

23. West Alyssa (2015). A Brief Review of Cognitive Theories in Gender Development. Behavioural Sciences Undergraduate Journal. 2. 59-66. 10.29173/bsuj288. 


\section{Annex 1: Checklist for Textbook Analysis}

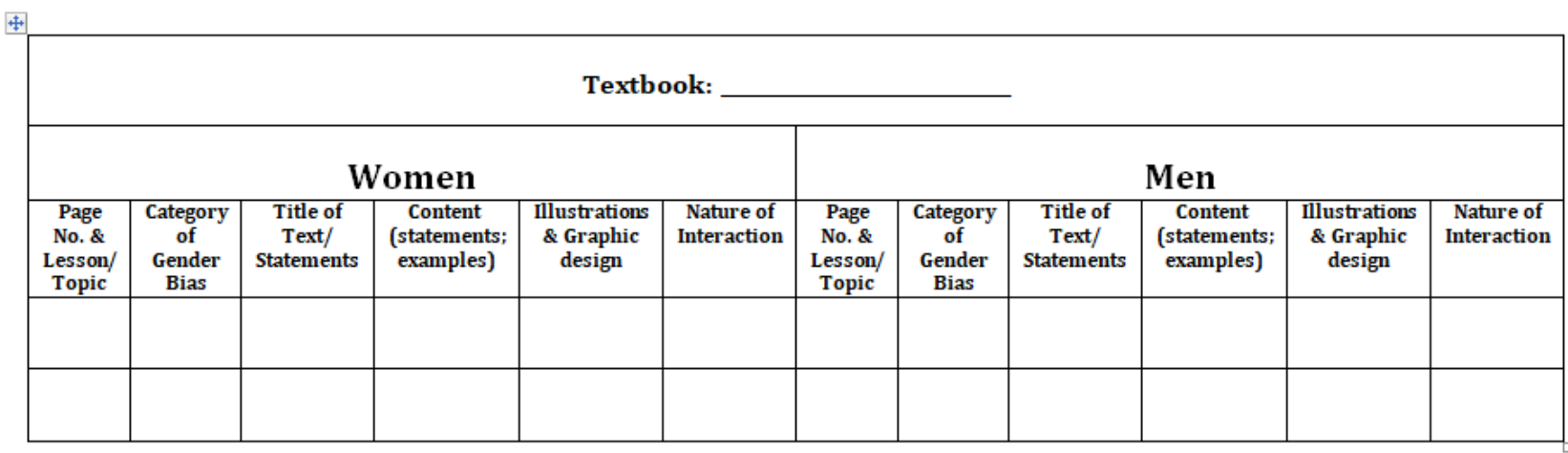

\begin{tabular}{|c|c|c|c|c|c|}
\hline \multicolumn{5}{|c|}{ Both Men and Women } \\
\hline $\begin{array}{c}\text { Page No. \& Lesson/ } \\
\text { Topic }\end{array}$ & $\begin{array}{c}\text { Category of Gender } \\
\text { Bias }\end{array}$ & $\begin{array}{c}\text { Title of Text/ } \\
\text { Statement }\end{array}$ & $\begin{array}{c}\text { Content } \\
\text { (statements; } \\
\text { example) }\end{array}$ & $\begin{array}{c}\text { Illustrations \& } \\
\text { Graphic Design }\end{array}$ & $\begin{array}{c}\text { Nature of } \\
\text { Interaction }\end{array}$ \\
\hline & & & & & \\
\hline
\end{tabular}

Age:

Gender:

Teaching Grade:

\section{Questions}

(1) In your opinion, what are the current roles of girls/women in the current Philippine educational set-up?

(2) In your opinion, what should be the roles of girls/women in the current Philippine educational set-up?

(3) In your opinion, do the reviewed primary education textbooks promote gender equality? In what ways?

(4) In your opinion, what are the aspects in primary textbooks that may contribute to gender equality? Be guided as follows:
a. Author's Gender
b. Statements about women/girls
c. Examples used in lessons
d. Illustrations

(5) What are your general ideas about a good book? 